\title{
CLINICAL PRACTICE RECOMMENDATIONS FOR THE MANAGEMENT AND PREVENTION OF CISPLATIN-INDUCED HEARING LOSS USING PHARMACOGENETIC MARKERS
}

Jong W. Lee ${ }^{1,2,3,10}$, Kusala Pussegoda ${ }^{3,10}$, Rod S. Rassekh ${ }^{2,3,4}$, Jose G. Monzon ${ }^{5}$, Geoffrey Liu ${ }^{6}$, Soomi Hwang ${ }^{7}$, Amit P. Bhavsar ${ }^{3,8}$, Sheila Pritchard ${ }^{3,4}$, Colin J. Ross ${ }^{1,2,3,8}$, Ursula Amstutz ${ }^{2,3,9,11}$, Bruce C. Carleton ${ }^{2,3,8,11}$, and the CPNDS clinical recommendations group ${ }^{12}$

${ }^{1}$ Center for Molecular Medicine and Therapeutics, Department of Medical Genetics, University of British Columbia, Vancouver, British Columbia, Canada; ${ }^{2}$ Pharmaceutical Outcomes Programme, British Columbia Children's Hospital, Vancouver, British Columbia, Canada; ${ }^{3}$ Child and Family Research Institute, Vancouver, British Columbia, Canada; ${ }^{4}$ Department of Pediatrics, Division of Pediatric Hematology/Oncology/Bone Marrow Transplant, British Columbia Children's Hospital, Vancouver, British Columbia, Canada; ${ }^{5}$ Department of Medical Oncology, Tom Baker Cancer Center, University of Calgary, Alberta, Canada; ${ }^{6}$ Department of Medical Oncology, Princess Margaret Cancer Center, University of Toronto, Toronto, Ontario, Canada; ${ }^{7}$ Faculty of Pharmaceutical Sciences, University of British Columbia, Vancouver, BC, Canada; ${ }^{8}$ Division of Translational Therapeutics, Department of Pediatrics, University of British Columbia, Vancouver, British Columbia; ${ }^{9}$ Institute of Clinical Chemistry, Inselspital Bern University Hospital, University of Bern, Switzerland.

${ }^{10}$ These authors contributed equally to this review

${ }^{11}$ These authors are co-senior authors to this work

${ }^{12}$ The Canadian Pharmacogenomics Network for Drug Safety (CPNDS) clinical recommendation group: Vancouver, BC, Canada: University of British Columbia, British Columbia Children's Hospital, Child and Family Research Institute: Bruce Carleton, Michael R. Hayden, Ursula Amstutz, Soomi Hwang, Colin J. Ross, Stuart MacLeod, Rod Rassekh, Anne Smith (deceased), Liam Brunham, Sheila Pritchard, Folefac Aminkeng. University of Calgary, Alberta, Canada: Jose Monzon. Toronto, ON, Canada: Sunnybrook Health Sciences Centre: Neil H. Shear; Hospital for Sick Children: Gideon Koren, Shinya Ito, Parvaz Madadi; Ontario Cancer Institute: Geoffrey Liu. London, ON, Canada: University of Western Ontario and London Health Sciences Centre: Michael J. Rieder, Richard Kim. Ottawa, ON, Canada: Department of National Defence: Maurica Maher. Indianapolis, IN, U.S.A: Indiana University: David Flockhart (deceased)

Corresponding Author: Correspondence and requests for materials should be addressed to Professor Bruce C. Carleton.

Canadian Pharmacogenomics Network for Drug Safety, Child and Family Research Institute, University of British Columbia, 950 West $28^{\text {th }}$ Avenue, Vancouver, BC V5Z 4H4, Tel.:+1 604-8753609, Fax: +1 604-875-2494, E-mail: bcarleton@popi.ubc.ca

\section{Funding:}

This work was funded through a Canadian Institutes of Health Research (CIHR) Meetings, Planning and Dissemination Grant - Knowledge Translation Supplement, FRN 114403. Additional funding was received 
from Genome British Columbia's Personalized Medicine Program and the BC Provincial Health Services

Authority

\begin{abstract}
:
Currently no pharmacogenomics-based criteria exist to guide clinicians in identifying individuals who are at risk of hearing loss from cisplatin-based chemotherapy. This review summarizes findings from pharmacogenomic studies that report genetic polymorphisms associated with cisplatin-induced hearing loss and aims to (1) provide up-to-date information on new developments in the field; (2) provide recommendations for the use of pharmacogenetic testing in the prevention, assessment and management of cisplatin-induced hearing loss in children and adults; and (3) identify knowledge gaps to direct and prioritize future research. These practice recommendations for pharmacogenetic testing in the context of cisplatin-induced hearing loss reflect a review and evaluation of recent literature and are designed to assist clinicians in providing optimal clinical care for patients receiving cisplatin based chemotherapy.
\end{abstract}

Keywords: Cisplatin, ototoxicity, hearing loss, pharmacogenetic testing, clinical practice recommendations

\title{
1. INTRODUCTION
}

\subsection{Cisplatin}

Cisplatin $\left(\right.$ PLATINOL $^{\circledR}$ ) is a widely used chemotherapeutic agent as a standard treatment for a variety of solid tumours. It is one of the most effective chemotherapeutic agents for children and has contributed to the dramatic increase in survival from many solid tumors including neuroblastoma, hepatoblastoma, brain tumors, osteosarcoma, and germ cell tumors. In fact, cisplatin has shown efficacy in standard risk hepatoblastoma, such that it can be used as monotherapy with an over $80 \%$ 3-year event-free survival ${ }^{1}$. Cisplatin is also used to treat a variety of adult cancers including ovarian, gastrointestinal, testicular, lung, and head and neck tumours ${ }^{2,3}$. A major complication that limits the clinical use of cisplatin is the risk of drug-induced ototoxicity that can result in life-long disability ${ }^{4}$. Cisplatin ototoxicity manifests as permanent, bilateral hearing loss which affects $10-25 \%$ of adults and $26-90 \%$ of children ${ }^{5-8}$. In particular, even mild hearing loss in children can significantly influence speech and language development, social-emotional development and increase the risk of learning difficulties 9 .

\subsection{Clinical presentation and assessment of cisplatin-induced hearing loss}

In patients receiving the same dose of cisplatin, the inter-individual variability of ototoxicity is profound, ranging from no hearing loss to high frequency hearing loss and progresses to severe hearing impairment in the speech frequencies ${ }^{10}$. Pure-tone audiometry measurements are used to determine the degree of hearing loss in patients, which is reported as a numeric grade. Several different grading criteria for ototoxicity have been developed over the years. The most commonly used methods are the Common Terminology Criteria for Adverse Events 4.0 (CTCAE) ENREF 15, ${ }^{11}$ and the Brock scale ${ }^{6}$ (Table 1). However, various other grading schemes exist such as the Muenster 
classification for early detection of hearing $\operatorname{loss}^{12}$, Chang scale ${ }^{13}$ and the recently developed International Society of Pediatric Oncology (SIOP) Boston Ototoxicity Grading Scale ${ }^{14}$. In standard treatment protocols, the occurrence of moderate to severe cisplatin ototoxicity leads to dose reduction or the termination of cisplatin treatment, which may affect survival rates ${ }^{15}$.

\subsection{Mechanisms influencing outcomes}

There is a significant amount of evidence suggesting that the major mechanism of action of cisplatin is the formation of intra-strand and inter-strand crosslinks with DNA. This activates multiple signal transduction pathways associated with cellular processes including cell-cycle arrest, DNA repair, and programmed cell death ${ }^{16}$. Platinum cochlear toxicity is thought to occur due to interference with signal transduction in the cochlea. Evidence indicates that cisplatin damage by apoptosis occurs at three sites in the cochlea: the outer hair cells in the organ of Corti, the spiral ganglion and the stria vascularis ${ }^{17}$.

Cisplatin-induced hearing loss is difficult to treat, primarily as the mechanisms involved in this process are not well understood. Several lines of evidence suggest that the generation of reactive oxygen species (ROS) are involved in the toxicity associated with cisplatin therapy ${ }^{18}$. ROSmediated damage occurs as a consequence of antioxidant depletion and increased lipid peroxidation in the cochlea. The increase in ROS has been reported to lead to morphological and functional changes in the organ of Corti ${ }^{19}$. The production of ROS changes acoustic transduction by modulating the outer hair cell motility in the organ of Corti resulting in cell death ${ }^{20}$.

\subsection{Risk factors for cisplatin-induced ototoxicity}

Clinical risk factors are known to influence the susceptibility of cisplatin-induced ototoxicity. These include cumulative cisplatin dose and dosing schedule, patient age at treatment, pre-existing hearing impairment, concomitant use of aminoglycosides and cranial irradiation (Box 1) ${ }^{21}$. It is now recognized that there is significant variability in hearing loss between individual patients receiving similar cumulative doses and application schedules of cisplatin suggesting that clinical risk factors alone are insufficient predictors of safety ${ }^{15}$.

Genetic variation in the genes involved in the biotransformation, transport, and targets of drugs have been recognized to influence patient drug response and susceptibility to adverse drug events, including ototoxicity ${ }^{22}$. Specific variations in the DNA sequence (single nucleotide polymorphisms (SNPs), insertions, deletions) that alter gene expression or protein function may thus influence the susceptibility to drug-induced toxicity and could facilitate the stratification of patients based on toxicity risk. To date, studies have implicated multiple genes in the susceptibility to cisplatininduced hearing loss. Specifically, genetic variants in methyltransferases (TPMT, COMT), transporters (ABCC3,CTR1), glutathione-S-transferases (GSTs), megalin (LRP2) and DNA repair genes $(X P C)$ have been associated with cisplatin-induced ototoxicity. ENREF 11 ENREF 30Evidence regarding associations of variation in these genes was reviewed and is summarized below (Section 2), with a more detailed summary provided in the Supplemental Material (http://links.lww.com/TDM/A140).

\subsection{Scope and purpose}

Currently no pharmacogenomics-based criteria exist to guide clinicians in identifying individuals who are at risk of cisplatin-induced hearing loss. This review is intended to (1) summarize and evaluate recent literature from pharmacogenomic studies that report associations of genetic polymorphisms with cisplatin-induced hearing loss to provide up to date information on new 
developments in the field; (2) provide recommendations for the use of pharmacogenetic testing in the prevention, assessment and management of cisplatin-induced hearing loss in children and adults; and (3) identify gaps in knowledge to direct and prioritize future research. These practice recommendations for pharmacogenetic testing in the context of cisplatin-induced hearing loss are designed to assist clinicians in providing optimal clinical care for patients receiving cisplatin based chemotherapy.

Specifically, recommendations are provided to address the following questions:

1. Should genetic testing be performed in patients with an indication for cisplatin therapy, in order to reduce the occurrence of cisplatin-induced hearing loss? What genes and gene variants should be tested?

2. Which patients should be tested and when?

3. How should patients undergoing cisplatin therapy be managed based on their genetic test results?

\section{SUMMARY OF SUPPORTING EVIDENCE}

\subsection{Methlytransferase genes (TPMT and COMT)}

Genetic polymorphisms in TPMT are implicated in the susceptibility to cisplatin-induced hearing loss in children (see detailed evidence summary in the supplementary materials and Supplementary Table S1, http://links.lww.com/TDM/A140). Specifically, TPMT variants rs12201199, rs1800460 and rs1142345 have been associated with ototoxicity in three independent pediatric cohorts ${ }^{15,23}$. These risk variants include the TPMT*3B, *3C and $* 3 A(* 3 B+* 3 C)$ loss of function alleles, which lead to rapid degradation of the TPMT proteins ${ }^{24}$. In a cohort of 317 children, $43(91.5 \%)$ carriers of the TPMT risk variant developed hearing loss compared to only four carriers $(8.5 \%)$ patients without hearing loss (Table S10), conferring a specificity of $96.8 \%$ and sensitivity of $22.3 \%{ }^{23}$. Three studies differing from the previous reports in patient cohorts and the treatment regimens used, reported non-significant associations between the TPMT variants and cisplatin-induced ototoxicity, however similar trends were observed in sub-cohorts of similarly treated patients ${ }^{25-27}$. Thus, evidence suggests an association of TPMT variants with cisplatin-induced hearing loss but with limitations in generalizability and the number of studies available (+++ evidence; Table 2).

Variants in COMT (rs9332377 and rs4646316) have shown similar trends of associations in four independent pediatric cohorts (Table S1) $)^{15,23,26}$. These associations reached statistical significance only in two of the four cohorts while two additional studies have also reported effect sizes in the opposite direction $^{25,27}$. Taken together, the evidence supporting the role of COMT is encouraging but requires further replication with specific attention to using comparable patient cohorts (++ evidence). COMT and TPMT enzymes utilize the same substrate, $S$-adenosylmethionine, and variants of these genes are hypothesized to alter cisplatin cytotoxicity by modulating cross-linking with purines in $\mathrm{DNA}^{15}$. Furthermore, $S$-adenosylmethionine has been demonstrated to increase cisplatin nephrotoxicity in rats $^{28}$.

\subsection{Cisplatin transporters $(A B C C 3, C T R 1)$}


To date, two studies reported associations of a synonymous variant in $A B C C 3$ (rs1051640) with cisplatin-induced hearing loss in pediatric patients (Table S2) ${ }^{15,23}$. ENREF 31ABCC3 is a transporter that mediates the efflux of organic anions, xenobiotics and glutathione $S$-conjugates, including glutathione S-conjugated cisplatin ${ }^{29,30}$. Reduced activity of ABCC3 may thus affect cisplatin detoxification through reduced transport of toxic compounds out of the cell. Evidence supporting a role of ABCC3 in cisplatin-induced ototoxicity is promising (++ evidence), but this association requires further replication to strengthen the current evidence. Furthermore, the functional consequences of the synonymous rs1051640 variant has yet to be identified and should be determined.

Copper transporter proteins $(C T R s)$ are major plasma membrane transporters that mediate both cisplatin uptake and export at the plasma membrane ${ }^{31}$. A study in non-small cell lung cancer patients treated with cisplatin reported a variant in CTRI (rs1098169) associated with increased ototoxicity in adults ${ }^{32}$. Independent replication and investigations in pediatric cohorts are necessary to extend this promising finding (++ evidence).

\subsection{Gluthathione S-Transferases (GSTs)}

One of the mechanisms of cisplatin detoxification is the conjugation of the active platinum metabolite with glutathione by glutathione s-transferases (GSTs) ${ }^{33,34}$. ENREF 42Several studies have therefore examined polymorphisms in GST genes (GSTM, GSTP, GSTT) in the context of cisplatin-induced hearing loss (Tables S3-S6) ${ }^{15,35-41}$.

One study reported a higher frequency of the $G S T M 3^{*} B$ allele in pediatric patients with normal hearing compared to patients with ototoxicity (Table S3) ${ }^{35}$. ENREF 50However, a second study investigating GST polymorphisms in ovarian cancer patients could not replicate this association ${ }^{38}(+$ evidence). In a study by Oldenburg et al., GSTP1 rs1965 was significantly associated with cisplatininduced ototoxicity in adult testicular cancer survivors (Table S4) ${ }^{36}$. However, this association did not achieve statistical significance in an extended patient cohort $^{37}$. Rednam et al. reported an opposite effect of GSTP1 rs1965 on cisplatin-induced hearing loss in a pediatric medulloblastoma cohort $^{42}$. Furthermore, five studies (4 pediatric, 1 adult) reported no significant association of GSTP1 with hearing loss ${ }^{15,23,35,37,38}$. Overall, evidence regarding an effect of GSTP1 rs 1695 on ototoxicity is thus inconsistent (Table S4) (+evidence). Finally, associations with cisplatin-induced ototoxicity have also been reported for GSTM1 (Table S5) ${ }^{36,37}$ and GSTT1 (Table S6) ${ }^{39}$. However, numerous other studies have not replicated these associations ${ }^{15,35-38,41,42}$ (+ evidence).

\section{ENREF 47}

\subsection{Megalin (LRP2)}

Two non-synonymous variants (rs2075252, rs2228171) in LRP2 have been examined in four different studies of children treated with cisplatin (Table S7) ${ }^{15,23,39,43}$. Riedemann et al. reported a significant association between rs2075252 and cisplatin-induced ototoxicity ${ }^{43}$. A nonsignificant trend for an association for rs2228171 was also identified. Conversely, Choeyprasert et al. found that rs2228171 was negatively associated with cisplatin-induced hearing loss with no association for rs $2075252^{39}$. In two additional large studies, both variants were not associated with cisplatininduced hearing loss in children ${ }^{15,23}$. Overall, given these inconsistent findings, further evidence is required to determine the relevance of rs2075252 and rs2228171 for cisplatin-induced ototoxicity (+ evidence). 


\subsection{DNA repair genes}

To date, the association of genetic variants in the DNA repair pathway with cisplatin-induced ototoxicity has been investigated in three studies (Table S8). A small study of pediatric and adult patients reported a significant association of a non-synonymous SNP in XPC rs2228001 with hearing loss ${ }^{44}$. However, this finding has yet to be replicated, with a lack of association reported in a larger pediatric cohort of 317 patients $^{23}$. Another independent study also did not observe any association of variants in ERCC1, XPD and XRCC1 with cisplatin ototoxicity (Table S8) ${ }^{38}$. Given the lack of replication, it is difficult to draw any conclusions about an effect of rs2228001 on cisplatin ototoxicity (+evidence).

\subsection{Genes associated with hereditary or age-related deafness}

Variants in GJB2, SLC26A4 and mitochondrial (mtDNA) polymorphisms in MTRNR1, MTTL1 and MTTS1 have been associated with aminoglycoside-mediated ototoxicity and progressive nonsyndromic high frequency hearing loss. Two studies investigating the role of mtDNA polymorphisms for cisplatin-induced hearing loss in children showed no evidence for a contribution of these variants to the susceptibility to cisplatin-induced hearing loss (Table S9) ${ }^{45,46}$. Therefore, there is currently no evidence to suggest an association of genes involved in hereditary deafness with cisplatin-induced ototoxicity (+ evidence). One study examining variants in otospiralin (Otos), an inner ear protein implicated with age-related hearing deterioration, reported a significant association between a protective haplotype and cisplatin-induced ototoxicity (Table S9) ${ }^{47}$. Although the evidence is limited at this time, these findings provide the basis for larger replication studies to validate this genetic association (++ evidence).

\section{CLINICAL PRACTICE RECOMMENDATIONS}

\section{$\underline{\text { Recommendations and considerations }}$}

3.1 Should genetic testing be performed in patients prior to initiation of cisplatin, in order to reduce the occurrence of cisplatin-induced hearing loss? What genes and gene variants should be tested?

There are genetic variants that should be tested in patients prior to initiation of cisplatin therapy to alert physicians and patients/families about the increased risk of cisplatin-induced hearing loss in susceptible patients.

\section{TPMT functional variants (A):}

Recommendation: We recommend pharmacogenetic testing for the associated functional TPMT variants $(* 3 A, * 3 B, * 3 C)$ and the known, relatively common, and functionally inactive $T P M T * 2$ variant in pediatric patients to receive cisplatin (level $\mathrm{A}$ - strong recommendation; Table 3).

Considerations: In over 95\% of Caucasian and Asian patients, low TPMT activity is explained by three alleles $(T P M T * 2, * 3 B \text {, and } * 3 C)^{48}$. In African populations, $* 3 C$ and $* 2$ are also common. All of these variants demonstrate reduced in vitro enzyme activity ${ }^{49}$. Around $10 \%$ of the population 
carry one of these TPMT risk variants, which account for approximately $25 \%$ of patients with ototoxicity (accounting for $27.9 \%, 21.9 \%$, and $24 \%$ of ototoxicity in 3 independent patient cohorts) ${ }^{15,23}$. Thus, the TPMT risk variants do not account for all cases of cisplatin ototoxicity. However, the high positive predictive value $(92 \%)$ of the TPMT variants indicates that a vast majority of patients who carry these variants develop hearing loss. The importance of identifying risk of hearing loss in children and the potential management strategies warrant a strong recommendation that children should be genotyped for risk variants in the TPMT gene. If genotyping is unavailable or impractical, TPMT phenotyping may be an alternative method to identify patients with low enzyme activity, even though this has not been investigated in any studies yet.

\section{Variants in COMT, $A B C C 3, C T R 1, G S T S$, $L R P 2$, DNA repair and deafness genes (C):}

Testing for variants in COMT, ABCC3, CTR1, GSTs, LRP2, DNA repair genes and genes associated with deafness is currently not recommended for clinical use (level $\mathrm{C}$ - optional recommendation). Further research is needed to determine the optimal strategy for the utilization of genotype information for these genes in therapeutic decision-making and strengthen the evidence supporting the genetic associations (see section 4).

\subsection{Which patients should be tested and when?}

\subsubsection{Pediatric patients}

Recommendation: Studies of pediatric oncology patients suggest that all children undergoing cisplatin therapy should be tested for genetic variants in TPMT (A). Ideally, children should be tested prior to the initiation of therapy to enable optimal consideration of therapeutic options in the context of genetic test results. However, the genetic test may also provide valuable information for patients who are already undergoing treatment, e.g. to guide decision-making on post-treatment follow-up.

Considerations: The current standard of care in pediatric oncology for treatment with cisplatin is to monitor hearing with audiograms before further doses of cisplatin are given. Patients who develop clinically significant hearing loss generally have a $50 \%$ reduction of subsequent doses of cisplatin ${ }^{50}$. Further hearing loss often results in complete elimination of cisplatin from the treatment plan. The use of pharmacogenetic information to define a patient at high risk of hearing loss can thus be used to consider potential dose reductions earlier in treatment. This approach is not much different than a dose reduction after toxicity onset, but allows the clinician to consider making this change sooner in the treatment plan. There are exceptions to this rule, such as cisplatin used in the treatment of hepatoblastoma, where no dose reduction is suggested at any point, given the critical role of cisplatin with regards to cure ${ }^{51,52}$. An important area of future investigation is how much sooner than actual toxicity (i.e., hearing loss) potential dose changes can be made without compromising cure rates.

\subsubsection{Adult patients}


Recommendation: Currently, the impact of the genetic variants recommended for testing in children is unknown in adult patients. At this point, genetic testing to identify patients at risk for cisplatin-induced hearing loss is NOT recommended in adult patients (C). This guideline will be updated to incorporate recommendations regarding genetic testing in adults as more studies become available. In the meantime, it is recommended that all adult patients to be treated with cisplatin receive audiometric testing before treatment initiation and at least one post-treatment followup to monitor the occurrence of cisplatin-induced hearing loss.

\subsection{How should patients undergoing cisplatin therapy be managed based on their genetic test results?}

The current endpoint for clinical intervention in cisplatin therapy is moderate to severe, irreversible hearing loss. By knowing in whom cisplatin hearing loss is likely to occur, clinicians have the possibility to consider altering therapy or monitoring before hearing loss occurs. Importantly, information gained from genetic testing should be used in the context of the unique circumstances of each individual patient to evaluate optimal treatment strategies, taking into consideration the balance between risk of toxicity and potential impact of management strategies on anti-tumour efficacy of therapy and cancer survival. Post-test treatment options will vary based on cancer type and should fall within the current guidelines and standards for cancer care. In the future, additional studies should be conducted to investigate the potential of individualized interventions based upon a patient's cisplatin pharmacogenetic risk factors.

In Table 4, a breakdown of the risk genotypes for cisplatin ototoxicity and their interpretations is provided. Based on the genetic variants currently recommended for pharmacogenetic testing, patients who carry ANY nonfunctional TPMT variant $(* 3 A, * 3 B, * 3 C, * 2)$ should be considered at high risk of cisplatin-induced hearing loss. In these patients, the following management options are recommended:

(1) Physicians are encouraged to consider the use of otoprotectants (i.e. amifostine, sodium thiosulfate) if the patient's tumour type is one for which otoprotectants may be effective to prevent cisplatin-induced ototoxicity without adversely affecting antitumour activity $(\mathrm{C}$; see section 2.9 in the supplementary materials, http://links.lww.com/TDM/A140, for a discussion of evidence on the effectiveness of otoprotectants). Current standard of care guidelines for the respective tumour types should be consulted to determine if otoprotectants are an option.

(2) Alternative treatments may be prescribed when they have demonstrated equal efficacy, manageable and acceptable toxicity, less ototoxicity, and are considered options within the current standards of care (C). For example, studies have reported similar outcomes in pediatric germ cell tumour patients treated using carboplatin, etoposide and bleomycin compared to treatment with cisplatin, etoposide and bleomycin but with less ototoxicity ${ }^{53,54}$ and treatment with carboplatin, etoposide and bleomycin has been suggested as an alternative treatment in young children ${ }^{55}$. A possible role for carboplatin has also been suggested in the treatment of neuroblastoma, where one study reported similar survival between patients receiving cisplatin therapy and patients receiving partial substitution of cisplatin therapy with carboplatin ${ }^{56}$. 
In adult patients, the substitution to carboplatin is not recommended as it is found to be inferior to cisplatin in therapeutic effectiveness for several tumours, such as testicular, bladder, head and neck cancers $^{57}$. Oxaliplatin however, has been investigated as an alternative to cisplatin in some tumour types. For example, oxaliplatin-based regimens have been recommended as an alternative to cisplatin-based therapy for the treatment of advanced gastric cancer ${ }^{58}$. Studies have also reported comparable outcomes to cisplatin-based therapy with reduced toxicity for advanced non-small-cell lung cancer ${ }^{59}$.

Considerations: Several factors must be considered when considering alternative treatments in patients at high risk of cisplatin-induced ototoxicity. These include goals of treatment, patient and physician preference, and socioeconomic considerations. For instance, the margin for acceptable toxicity risk may be much lower for treatments that are merely palliative in nature versus those with curative intent. In addition, patient preference may play an important role in the decision to use an alternative treatment. For example, a professional musician may not wish to risk any level of ototoxicity. This lowered margin for acceptable risk also holds true in the situation where alternative, equally effective treatments are available, albeit at an increased financial or clinical cost.

(3) Where appropriate, physicians are encouraged to increase monitoring in high-risk patients (C). In these cases, increased monitoring may lead to earlier detection of hearing loss and allow physicians to implement alternative methods of treatment earlier to prevent further damage, such as the above recommendations. Similarly, management of hearing loss (speech therapy, hearing aids) may be initiated earlier to facilitate language development in children and minimize learning and social difficulties associated with hearing loss.

(4) High risk patients should be encouraged to receive more frequent follow-up audiometric hearing tests after treatment has ended (C). These are usually offered as standard care by medical service plans.

Considerations: Current Children's Oncology Group (COG) recommendations for audiological screening for children treated with cisplatin suggest that all subjects have full hearing testing at the conclusion of their treatment or at the transition to a survivorship clinic. No further hearing testing at a later time point is recommended by the COG except in situations where there are specific clinical concerns. Similarly, there are currently no guidelines as to when audiogram hearing tests should be conducted post therapy. However, there is evidence that cisplatin can be isolated in the inner ear 20 years post therapy ${ }^{60}$. Moreover, there are recent reports of late onset hearing loss occurring after treatment with cisplatin ${ }^{61}$. Therefore, additional and long-term follow-up investigating hearing outcomes should be considered in high-risk patients. In particular, follow-up tests may be missed by patients living in remote areas, until severe hearing loss occurs, at which time there are no preventative options to consider. The optimal frequency and duration of audiometric hearing tests post therapy remains unknown and requires further study.

\section{FUTURE DIRECTIONS}




\subsection{Standardized clinical classification of cisplatin-induced hearing loss}

Currently, a major challenge in assessing cisplatin-induced ototoxicity is the lack of a standardized grading scheme of patient hearing in all studies. Several different grading criteria are available, which are inconsistently used to phenotype patients. This can lead to discrepancies in research findings and difficulties comparing results between studies as differences in the classification of patients can significantly alter the results of an association study. For clinical application, it is essential to validate genetic findings in independent patient cohorts for assessment of reproducibility and generalizability. A standardized phenotyping method would significantly facilitate accurate replication studies, and enable cross-study comparison of research findings.

\subsection{Analyses of associated variants in additional patient populations}

It is important to recognize that children and adults metabolize, distribute and eliminate certain drugs differently, which could result in different genetic variants being responsible for cisplatininduced toxicity. The importance of genetic risk variants may also differ between treatments for different malignancies due to differences in treatment protocols. However, due to limited sample sizes it has been difficult to carry out subgroup analyses to determine whether genetic associations are specific to certain treatment protocols. For example, based on a recent study ${ }^{25}$, a possible impact of concomitant amifostine or craniospinal irradiation on the association of TPMT and COMT variants with cisplatin-induced hearing loss in children requires further investigation to ascertain the impact of these confounding factors on genetic associations. In addition, a majority of studies have been carried out in populations of European ancestry. Whether these same genetic variants are also associated in different patient populations with other ancestries still needs to be investigated. Due to these potential differences between patient populations, the genetic testing recommendations provided here currently apply only for cisplatin therapy in children. Studies in adult patients are underway and are expected to become available in the near future to provide information on the relevance of these gene variants in the adult population.

ENREF 52

\subsection{Predictive modeling to combine genetic and clinical risk factors}

Multi-marker predictive models combine the effects of several genes and/or clinical factors into one predicted outcome. Pussegoda et al. developed a predictive model that includes the COMT and $A B C C 3$ variants, along with TPMT variants ${ }^{23}$. In this model, based on currently available evidence, the COMT and $A B C C 3$ variants do not contribute to the prediction of patients at high risk of cisplatin-induced ototoxicity (supplementary materials, http://links.lww.com/TDM/A140). Instead, the model suggests that the COMT and $A B C C 3$ genotypes may enable the stratification of patients between intermediate and lower risk. However, additional research is needed on how to optimally incorporate genetic information from these genes to improve the prediction of low versus intermediate risk patients, and on how to optimally adjust therapy in these risk groups. For example, whether patients at low risk need less intensive monitoring or could be treated with higher doses to improve survival without increasing cisplatin-induced hearing loss requires further investigation. Furthermore, other genetic variants that demonstrate reproducible associations should also be incorporated into risk prediction models in order to assess their optimal use for patient stratification. In addition to genetic factors, clinical factors affecting the risk of ototoxicity should be included in such a predictive model. The evidence of clinical risk factors in cisplatin-induced deafness has not been systematically reviewed in this guideline and is therefore not included in current recommendations. However, the combined inclusion of clinical and genetic risk factors may improve the stratification of patients at high risk compared to using genetic risk factors alone. 
Ultimately, by including both clinical and genetic factors into a model it may be possible to move to a simple risk score-based model to classify patients as high, intermediate and low risk.

\subsection{Prospective studies, alternative treatments, cost effectiveness}

All genetic association studies for cisplatin-induced ototoxicity thus far have been retrospective. The recommendations at this time are therefore based on retrospective evidence of clinical validity. It will be important to prospectively investigate the clinical utility of these tests in the future. In addition, prospective studies are needed to optimize the real-world clinical utility (effectiveness) of predictive pharmacogenetic testing by evaluating additional therapeutic options in high-risk patients in the context of therapeutic effectiveness and patient survival. In particular, further studies are needed to investigate the use of alternative medications (e.g. carboplatin, oxaliplatin), as well as alternative administration routes (e.g. continuous infusion vs. bolus) of cisplatin in high-risk patients. For example, even though evidence is ambiguous regarding the overall risk of hearing loss for continuous infusion vs. bolus administration of cisplatin ${ }^{62}$, it is possible that a different administration route provides an advantage specifically for patients with a genetically increased risk for ototoxicity.

Similarly, it is important to conduct prospective trials to confirm whether otoprotective agents are effective in protecting against ototoxicity in children treated with cisplatin and other platinum based chemotherapy agents. Future trials should assess large patient cohorts stratified by genetic ototoxicity risk factors for outcomes including ototoxcity, anti-tumour efficacy, adverse effects and quality of life. A few phase III trials are currently ongoing in pediatric patients to assess whether sodium thiosulfate (STS) and amifostine can prevent hearing loss in children while maintaining efficacy of chemotherapy. Additional large clinical trials with amifostine, STS and other otoprotective agents such as N-acetyl cysteine (NAC) and D-methionine should be carried out in both adults and children with a variety of different tumour types to strengthen evidence and enable conclusions about their effectiveness.

The provided recommendations only include clinical actions that fall within current standards of care, such as increased monitoring and alternative chemotherapy drugs that are within standard treatment protocols. In the future, new evidence may support the use of alternative cisplatin dosing or new otoprotective strategies. The recommendations in this guideline are thus considered iterative, and should continue to build upon new evidence as it is generated. Updates of recommendations are planned on a regular basis to incorporate new evidence. Finally, as genetic testing for cisplatininduced hearing loss is used more frequently, an evaluation of the cost-effectiveness of genetic testing will become increasingly important and should be performed.

\section{METHODS}

The same literature review, evidence appraisal, and recommendation development process was followed as described previously ${ }^{63,64}$. In brief, a standard guideline development process was followed, in accordance with the quality criteria suggested by the Appraisal of Guidelines Research and Evaluation Enterprise (AGREE) ${ }^{65}$. Following a systematic literature search, critical appraisal of 
evidence was performed (Table 2), with specific considerations for quality and number of studies, consistency of results and magnitude of the effect. Recommendations were developed during a meeting of guideline development group members, with each recommendation assigned a level of strength, based upon the robustness of the underlying evidence, the balance between benefits and risks of genetic testing and genotype-guided treatment, as well as the likelihood of variability in a patient's values and preferences (Table 3). Internal and external review by development group members, subject experts and members of the intended target audience was performed. A detailed description of the literature search strategy is provided in the Supplementary Materials (http://links.lww.com/TDM/A140) along with further details on the intended target audience and scope of this document, and the recommendation development group.

\section{ACKNOWLEDGMENTS}

We would like to thank Tricia Yu from the UBC Eric Hamber Library for reviewing the literature search strategy and Gabriella Groeneweg for her contributions to the management of this project and the organization of the recommendation development workshop.

\section{DISCLOSURE OR CONFLICTS OF INTEREST}

Bruce Carleton, Colin Ross and Michael Hayden are inventors on patents and patent applications that relate to genetic polymorphisms that are predictive of hearing loss after treatment with cisplatin.

\section{REFERENCES}

1. Perilongo $G$, Maibach $R$, Shafford $E$, et al. Cisplatin versus cisplatin plus doxorubicin for standardrisk hepatoblastoma. N Engl J Med. Oct 22 2009;361(17):1662-1670.

2. Helm CW, States JC. Enhancing the efficacy of cisplatin in ovarian cancer treatment - could arsenic have a role. J Ovarian Res. 2009;2:2.

3. Hohnloser JH, Schierl R, Hasford B, Emmerich B. Cisplatin based chemotherapy in testicular cancer patients: long term platinum excretion and clinical effects. Eur J Med Res. Sep 20 1996;1(11):509514.

4. Kling J. US FDA contemplates collection of pharmacogenomic data. Nat Biotechnol. Jun 2003;21(6):590.

5. Li Y, Womer RB, Silber JH. Predicting cisplatin ototoxicity in children: the influence of age and the cumulative dose. Eur J Cancer. Nov 2004;40(16):2445-2451.

6. Brock PR, Bellman SC, Yeomans EC, Pinkerton CR, Pritchard J. Cisplatin ototoxicity in children: a practical grading system. Med Pediatr Oncol. 1991;19(4):295-300.

7. Blakley BW, Myers SF. Patterns of hearing loss resulting from cis-platinum therapy. Otolaryngol Head Neck Surg. Sep 1993;109(3 Pt 1):385-391.

8. Skinner R, Pearson AD, Amineddine HA, Mathias DB, Craft AW. Ototoxicity of cisplatinum in children and adolescents. Br J Cancer. Jun 1990;61(6):927-931.

9. Blair J.C. PME, Viehweg S.H. The effects of mild sensorineural hearing loss on academic performance of young school age children. Volta Rev. 1985 2001;87:87-93. 
10. Lewis MJ, DuBois SG, Fligor B, Li X, Goorin A, Grier HE. Ototoxicity in children treated for osteosarcoma. Pediatr Blood Cancer. Mar 2009;52(3):387-391.

11. Cancer Therapy Evalution Program-Common Terminology Criteria for Adverse Events-Version 4.03. 2010.

12. Schmidt CM, Bartholomaus E, Deuster D, Heinecke A, Dinnesen AG. [The "Muenster classification" of high frequency hearing loss following cisplatin chemotherapy]. Hno. Apr 2007;55(4):299-306.

13. Chang KW, Chinosornvatana N. Practical grading system for evaluating cisplatin ototoxicity in children. J Clin Oncol. Apr 1;28(10):1788-1795.

14. Brock PR, Knight KR, Freyer DR, et al. Platinum-induced ototoxicity in children: a consensus review on mechanisms, predisposition, and protection, including a new International Society of Pediatric Oncology Boston ototoxicity scale. J Clin Oncol. Jul 1 2012;30(19):2408-2417.

15. Ross CJ, Katzov-Eckert H, Dube MP, et al. Genetic variants in TPMT and COMT are associated with hearing loss in children receiving cisplatin chemotherapy. Nat Genet. Dec 2009;41(12):1345-1349.

16. Persons DL, Yazlovitskaya EM, Cui W, Pelling JC. Cisplatin-induced activation of mitogen-activated protein kinases in ovarian carcinoma cells: inhibition of extracellular signal-regulated kinase activity increases sensitivity to cisplatin. Clin Cancer Res. May 1999;5(5):1007-1014.

17. Kim HJ, Lee JH, Kim SJ, et al. Roles of NADPH oxidases in cisplatin-induced reactive oxygen species generation and ototoxicity. J Neurosci. Mar 17 2010;30(11):3933-3946.

18. Rybak LP, Mukherjea D, Jajoo S, Ramkumar V. Cisplatin Ototoxicity and Protection: Clinical and Experimental Studies. Tohoku J Exp Med. Nov 2009;219(3):177-186.

19. Ravi R, Somani SM, Rybak LP. Mechanism of cisplatin ototoxicity: antioxidant system. Pharmacol Toxicol. Jun 1995;76(6):386-394.

20. van Ruijven MW, de Groot JC, Smoorenburg GF. Time sequence of degeneration pattern in the guinea pig cochlea during cisplatin administration. A quantitative histological study. Hear Res. Nov 2004;197(1-2):44-54.

21. Langer T, am Zehnhoff-Dinnesen A, Radtke S, Meitert J, Zolk O. Understanding platinum-induced ototoxicity. Trends Pharmacol Sci. 2013;34(8):458-469.

22. Wang L, McLeod HL, Weinshilboum RM. Genomics and drug response. N Engl J Med. Mar 24 2011;364(12):1144-1153.

23. Pussegoda K, Ross CJ, Visscher H, et al. Replication of TPMT and ABCC3 genetic variants highly associated with cisplatin-induced hearing loss in children. Clin Pharmacol Ther. Aug 2013;94(2):243251.

24. Oliveira E, Quental S, Alves S, Amorim A, Prata MJ. Do the distribution patterns of polymorphisms at the thiopurine S-methyltransferase locus in sub-Saharan populations need revision? Hints from Cabinda and Mozambique. Eur J Clin Pharmacol. Jul 2007;63(7):703-706.

25. Yang J, Lim J, Huang J, et al. The role of inherited TPMT and COMT genetic variation in cisplatininduced ototoxicity in children with cancer. Clin Pharmacol Ther. 2013;94(2):252-259.

26. Lanvers-Kaminsky C, Malath I, Deuster D, Ciarimboli G, Boos J, Am Zehnhoff-Dinnesen AG. Evaluation of Pharmacogenetic Markers to Predict the Risk of Cisplatin-Induced Ototoxicity. Clin Pharmacol Ther. Mar 182014.

27. Hagleitner MM, Coenen MJ, Patino-Garcia A, et al. Influence of Genetic Variants in TPMT and COMT Associated with Cisplatin Induced Hearing Loss in Patients with Cancer: Two New Cohorts and a Meta-Analysis Reveal Significant Heterogeneity between Cohorts. PloS one. 2014;9(12):e115869.

28. Ochoa B, Bobadilla N, Arrellin G, Herrera LA. S-Adenosyl-L-methionine increases serum BUN and creatinine in cisplatin-treated mice. Arch Med Res. Jan 2009;40(1):54-58.

29. Ballatori N, Hammond CL, Cunningham JB, Krance SM, Marchan R. Molecular mechanisms of reduced glutathione transport: role of the MRP/CFTR/ABCC and OATP/SLC21A families of membrane proteins. Toxicol Appl Pharmacol. May 1 2005;204(3):238-255. 
30. Lee YM, Cui Y, Konig J, et al. Identification and functional characterization of the natural variant MRP3-Arg1297His of human multidrug resistance protein 3 (MRP3/ABCC3). Pharmacogenetics. Apr 2004;14(4):213-223.

31. Ishida S, Lee J, Thiele DJ, Herskowitz I. Uptake of the anticancer drug cisplatin mediated by the copper transporter Ctr1 in yeast and mammals. Proc Natl Acad Sci USA. 2002;99(22):14298-14302.

32. Xu X, Ren H, Zhou B, et al. Prediction of copper transport protein 1 (CTR1) genotype on severe cisplatin induced toxicity in non-small cell lung cancer (NSCLC) patients. Lung Cancer. 2012;77(2):438-442.

33. Yang P, Ebbert JO, Sun Z, Weinshilboum RM. Role of the glutathione metabolic pathway in lung cancer treatment and prognosis: a review. J Clin Oncol. Apr 10 2006;24(11):1761-1769.

34. Leitner HM, Kachadourian R, Day BJ. Harnessing drug resistance: using ABC transporter proteins to target cancer cells. Biochem Pharmacol. Dec 15 2007;74(12):1677-1685.

35. Peters U, Preisler-Adams S, Hebeisen A, et al. Glutathione S-transferase genetic polymorphisms and individual sensitivity to the ototoxic effect of cisplatin. Anticancer Drugs. Sep 2000;11(8):639-643.

36. Oldenburg J, Kraggerud SM, Cvancarova M, Lothe RA, Fossa SD. Cisplatin-induced long-term hearing impairment is associated with specific glutathione s-transferase genotypes in testicular cancer survivors. J Clin Oncol. Feb 20 2007;25(6):708-714.

37. Oldenburg J, Kraggerud SM, Brydoy M, Cvancarova M, Lothe RA, Fossa SD. Association between long-term neuro-toxicities in testicular cancer survivors and polymorphisms in glutathione-stransferase-P1 and -M1, a retrospective cross sectional study. J Trans/ Med. 2007;5:70.

38. Khrunin AV, Moisseev A, Gorbunova V, Limborska S. Genetic polymorphisms and the efficacy and toxicity of cisplatin-based chemotherapy in ovarian cancer patients. Pharmacogenomics J. Feb 2010;10(1):54-61.

39. Choeyprasert W, Sawangpanich R, Lertsukprasert K, et al. Cisplatin-induced ototoxicity in pediatric solid tumors: the role of glutathione S-transferases and megalin genetic polymorphisms. J Pediatr Hematol Oncol. May 2013;35(4):e138-143.

40. Rednam S, Scheurer ME, Adesina A, Lau CC, Okcu MF. Glutathione S-transferase P1 single nucleotide polymorphism predicts permanent ototoxicity in children with medulloblastoma. Pediatr Blood Cancer. Apr 2013;60(4):593-598.

41. Barahmani N, Carpentieri S, Li XN, et al. Glutathione S-transferase M1 and T1 polymorphisms may predict adverse effects after therapy in children with medulloblastoma. Neurooncol. Jun 2009;11(3):292-300.

42. Rednam S, Scheurer M, Adesina A, Lau C, Okcu M. Glutathione S-transferase P1 single nucleotide polymorphism predicts permanent ototoxicity in children with medulloblastoma. Pediatr Blood Cancer. 2013;60(4):593-598.

43. Riedemann L, Lanvers C, Deuster D, et al. Megalin genetic polymorphisms and individual sensitivity to the ototoxic effect of cisplatin. Pharmacogenomics J. Feb 2008;8(1):23-28.

44. Caronia D, Patino-Garcia A, Milne RL, et al. Common variations in ERCC2 are associated with response to cisplatin chemotherapy and clinical outcome in osteosarcoma patients. Pharmacogenomics J. Oct 2009;9(5):347-353.

45. Knoll C, Smith RJ, Shores C, Blatt J. Hearing genes and cisplatin deafness: a pilot study. Laryngoscope. Jan 2006;116(1):72-74.

46. Peters U, Preisler-Adams S, Lanvers-Kaminsky C, Jurgens H, Lamprecht-Dinnesen A. Sequence variations of mitochondrial DNA and individual sensitivity to the ototoxic effect of cisplatin. Anticancer Res. Mar-Apr 2003;23(2b):1249-1255.

47. Spracklen TF, Whitehorn H, Vorster AA, Ramma L, Dalvie S, Ramesar RS. Genetic variation in Otos is associated with cisplatin-induced ototoxicity. Pharmacogenomics. 2014;15(13):1667-1676.

48. Krynetski E, Evans WE. Drug methylation in cancer therapy: lessons from the TPMT polymorphism. Oncogene. Oct 20 2003;22(47):7403-7413. 
49. Salavaggione OE, Wang L, Wiepert M, Yee VC, Weinshilboum RM. Thiopurine S-methyltransferase pharmacogenetics: variant allele functional and comparative genomics. Pharmacogenet Genomics. Nov 2005;15(11):801-815.

50. Packer RJ, Gajjar A, Vezina G, et al. Phase III study of craniospinal radiation therapy followed by adjuvant chemotherapy for newly diagnosed average-risk medulloblastoma. J Clin Oncol. Sep 1 2006;24(25):4202-4208.

51. Katzenstein HM, London WB, Douglass EC, et al. Treatment of unresectable and metastatic hepatoblastoma: a pediatric oncology group phase II study. J Clin Oncol. Aug 15 2002;20(16):34383444.

52. Perilongo G, Shafford E, Maibach R, et al. Risk-adapted treatment for childhood hepatoblastoma. final report of the second study of the International Society of Paediatric Oncology--SIOPEL 2. Eur J Cancer. Feb 2004;40(3):411-421.

53. Mann JR, Raafat F, Robinson K, et al. The United Kingdom Children's Cancer Study Group's second germ cell tumor study: carboplatin, etoposide, and bleomycin are effective treatment for children with malignant extracranial germ cell tumors, with acceptable toxicity. J Clin Oncol. Nov 15 2000;18(22):3809-3818.

54. Stern JW, Bunin N. Prospective study of carboplatin-based chemotherapy for pediatric germ cell tumors. Med Pediatr Oncol. Sep 2002;39(3):163-167.

55. Shaikh F, Nathan PC, Hale J, Uleryk E, Frazier L. Is there a role for carboplatin in the treatment of malignant germ cell tumors? A systematic review of adult and pediatric trials. Pediatr Blood Cancer. Apr 2012;60(4):587-592.

56. Simon T, Hero B, Dupuis W, Selle B, Berthold F. The incidence of hearing impairment after successful treatment of neuroblastoma. Klinische Padiatrie. Jul-Aug 2002;214(4):149-152.

57. Lokich J, Anderson N. Carboplatin versus cisplatin in solid tumors: an analysis of the literature. Ann Oncol. Jan 1998;9(1):13-21.

58. Mackenzie M, Spithoff $K$, Jonker $D$. Systemic therapy for advanced gastric cancer: a clinical practice guideline. Curr Oncol. Aug 2011;18(4):e202-209.

59. Raez LE, Kobina S, Santos ES. Oxaliplatin in first-line therapy for advanced non-small-cell lung cancer. Clin Lung Cancer. Jan 2010;11(1):18-24.

60. Gelevert T, Messerschmidt J, Meinardi MT, et al. Adsorptive voltametry to determine platinum levels in plasma from testicular cancer patients treated with cisplatin. Ther Drug Monit. Apr 2001;23(2):169-173.

61. Kolinsky DC, Hayashi SS, Karzon R, Mao J, Hayashi RJ. Late onset hearing loss: a significant complication of cancer survivors treated with Cisplatin containing chemotherapy regimens. $J$ Pediatr Hematol Oncol. Mar 2010;32(2):119-123.

62. Gupta AA, Capra M, Papaioannou V, et al. Low incidence of ototoxicity with continuous infusion of cisplatin in the treatment of pediatric germ cell tumors. J Pediatr Hematol Oncol. Feb 2006;28(2):91-94.

63. Madadi P, Amstutz U, Rieder M, et al. Clinical practice guideline: CYP2D6 genotyping for safe and efficacious codeine therapy. J Popul Ther Clin Pharmacol. 2013;20(3):96.

64. Amstutz $U$, Shear N, Rieder M, et al. Recommendations for HLA-B*15:02 and HLA-A*31:01 genetic testing to reduce the risk of carbamazepine-induced hypersensitivity reactions. Epilepsia. 2014.

65. Brouwers MC, Kho ME, Browman GP, et al. AGREE II: advancing guideline development, reporting and evaluation in health care. CMAJ. Dec 14 2010;182(18):E839-842.

66. Chang KW, Chinosornvatana N. Practical grading system for evaluating cisplatin ototoxicity in children. J Clin Oncol. Apr 1 2010;28(10):1788-1795.

67. Rebecca LR, Richard BG, Martin AK, Murray LB. Beyond TPMT: genetic influences on thiopurine drug responses in inflammatory bowel disease. Personalized Med. 2008;5(3):233-248. 
68. Gil AM, David MA, Richard MD, et al. An integrated map of genetic variation from 1,092 human genomes. Nature. 2012;491(7422):56-65.

69. Bokemeyer C, Berger CC, Hartmann JT, et al. Analysis of risk factors for cisplatin-induced ototoxicity in patients with testicular cancer. Br J Cancer. Apr 1998;77(8):1355-1362.

70. Kushner BH, Budnick A, Kramer K, Modak S, Cheung NK. Ototoxicity from high-dose use of platinum compounds in patients with neuroblastoma. Cancer. Jul 15 2006;107(2):417-422.

71. Li Y, Womer RB, Silber JH. Predicting cisplatin ototoxicity in children: the influence of age and the cumulative dose. Eur J Cancer. 2004;40(16):2445-2451.

72. Yancey A, Harris MS, Egbelakin A, Gilbert J, Pisoni DB, Renbarger J. Risk factors for cisplatinassociated ototoxicity in pediatric oncology patients. Pediatr Blood Cancer. Jul 15 2012;59(1):144148.

73. Schacht J, Talaska AE, Rybak LP. Cisplatin and aminoglycoside antibiotics: hearing loss and its prevention. Anat Rec (Hoboken). 2012;295(11):1837-1850.

74. Grau C, Moller K, Overgaard M, Overgaard J, Elbrond O. Sensori-neural hearing loss in patients treated with irradiation for nasopharyngeal carcinoma. Int J Rad Oncol Biol Phys. Aug 1991;21(3):723-728.

75. Warrier R, Chauhan A, Davluri M, Tedesco SL, Nadell J, Craver R. Cisplatin and cranial irradiationrelated hearing loss in children. Ochsner J. Fall 2012;12(3):191-196.

\section{Box 1. Clinical risk factors for cisplatin-induced ototoxicity}

- Higher cisplatin cumulative dose and bolus administration of cisplatin dose $e^{62,69}$. Total dose also associated with severity; patients at risk of developing hearing loss in the speech frequencies when doses exceed $400 \mathrm{mg} / \mathrm{m}^{270}$.

- Younger age at time of treatment, patients less than 5 years of age have 20 times higher risk compared to similarly treated older patients ${ }^{71}$. Age reported to have inverse relationship with hearing loss severity ${ }^{72}$.

- Aminoglycoside antibiotics share similar toxicity profile with cisplatin, causing nephrototoxicity, neuropathy and ototoxicity ${ }^{73}$.

- Cranial irradiation can cause irreversible hearing loss independently and with greater effect in combination with cisplatin ${ }^{74,75}$. 
Table 1: Criteria used to determine the grade of cisplatin-induced hearing loss in patients

\begin{tabular}{|c|c|c|c|c|c|}
\hline $\begin{array}{l}\text { Grading } \\
\text { Scheme }\end{array}$ & $\begin{array}{c}\text { Grade 0 } \\
\text { Normal Hearing }\end{array}$ & $\begin{array}{c}\text { Grade } 1 \\
\text { Mild Hearing Loss }\end{array}$ & $\begin{array}{c}\text { Grade } 2 \\
\text { Moderate Hearing Loss }\end{array}$ & $\begin{array}{c}\text { Grade } 3 \\
\text { Severe Hearing Loss }\end{array}$ & $\begin{array}{c}\text { Grade } 4 \\
\text { Severe Hearing Loss }\end{array}$ \\
\hline $\begin{array}{c}\text { CTCAE Criteria } \\
4.03^{15}\end{array}$ & $\begin{array}{c}<20 \mathrm{~dB} \text { hearing } \\
\text { loss at all } \\
\text { frequencies }\end{array}$ & $\begin{array}{c}\text { Hearing loss of } \geq 20 \mathrm{~dB} \\
\text { at } 8 \mathrm{kHz}\end{array}$ & $\begin{array}{c}\text { Hearing loss of } \geq 20 \mathrm{~d} \\
8 \mathrm{kHz}\end{array}$ & $\begin{array}{c}\text { Hearing loss of } \geq 20 \mathrm{~dB} \\
\text { at } 2-8 \mathrm{kHz}\end{array}$ & $\begin{array}{c}\text { Hearing loss of } \geq 40 \mathrm{~dB} \\
\text { at } 1-8 \mathrm{kHz}\end{array}$ \\
\hline Brock Criteria $^{6}$ & $\begin{array}{c}<40 \mathrm{~dB} \text { hearing } \\
\text { loss at all } \\
\text { frequencies }\end{array}$ & $\begin{array}{c}\text { Hearing loss of } \geq 40 \mathrm{~dB} \\
\text { at } 8 \mathrm{kHz}\end{array}$ & $\begin{array}{c}\text { Hearing loss of } \geq 40 \mathrm{~dB} \text { at } 4 \\
\mathrm{kHz} \text { and above }\end{array}$ & $\begin{array}{l}\text { Hearing loss of } \geq 40 \mathrm{~dB} \\
\text { at } 2 \mathrm{kHz} \text { and above }\end{array}$ & $\begin{array}{l}\text { Hearing loss of } \geq 40 \mathrm{~dB} \\
\text { at } 1 \mathrm{kHz} \text { and above }\end{array}$ \\
\hline $\begin{array}{l}\text { Muenster } \\
\text { Criteria }^{16}\end{array}$ & $\begin{array}{l}<10 \mathrm{~dB} \text { at all } \\
\text { frequencies }\end{array}$ & $\begin{array}{c}>10 \text { to }<20 \mathrm{~dB} \text { at all } \\
\text { frequencies }\end{array}$ & $\begin{aligned} \text { Hearing loss } \geq 4 \mathrm{kHz}, & >20 \mathrm{~dB} \\
2 \mathrm{a}:>20 \text { to } & \leqslant 40 \mathrm{~dB} \\
2 \mathrm{~b}: & >40 \text { to } \leqslant 60 \mathrm{~dB} \\
2 \mathrm{c}: & >60 \mathrm{~dB}\end{aligned}$ & $\begin{array}{l}\stackrel{\text { Hearing loss }<4 \mathrm{kHz}}{\quad>20 \mathrm{~dB}} \\
\text { 3a: }>20 \text { to } \leqslant 40 \mathrm{~dB} \\
3 \mathrm{~b}:>40 \text { to } \leqslant 60 \mathrm{~dB} \\
\text { 3c: }>60 \mathrm{~dB}\end{array}$ & $\begin{array}{c}\text { Mean hearing loss } \\
<4 \mathrm{kHz} ; \geq 80 \mathrm{Db}\end{array}$ \\
\hline Chang Criteria $^{75}$ & $\begin{array}{c}<20 \mathrm{~dB} \text { at } 1,2, \\
\text { and } 4 \mathrm{kHz}\end{array}$ & $\begin{array}{c}\text { Hearing loss of } \\
\text { 1a: } \geq 40 \mathrm{~dB} \text { at } 6-12 \mathrm{kHz} \\
\text { 1b: }>20 \text { to }<40 \mathrm{~dB} \text { at } \\
4 \mathrm{kHz}\end{array}$ & $\begin{array}{c}\text { Hearing loss of } \\
\text { 2a: } \geq 40 \mathrm{~dB} \text { at } 4 \mathrm{kHz} \text { and } \\
\text { above } \\
\text { 2b: }>20 \text { to }<40 \mathrm{~dB} \text { below } \\
4 \mathrm{kHz}\end{array}$ & $\begin{array}{c}\text { Hearing loss of } \geq 40 \mathrm{~dB} \\
\text { at } 2 \text { or } 3 \mathrm{kHz}\end{array}$ & $\begin{array}{c}\text { Hearing loss of } \geq 40 \mathrm{~dB} \\
\text { at } 1 \mathrm{kHz}\end{array}$ \\
\hline $\begin{array}{l}\text { SIOP Boston } \\
\text { Criteria }^{18}\end{array}$ & $\begin{array}{c}<20 \mathrm{~dB} \text { hearing } \\
\text { loss at all } \\
\text { frequencies }\end{array}$ & $\begin{array}{c}\text { Hearing loss of > } 20 \mathrm{~dB} \\
\text { above } 4 \mathrm{kHz}\end{array}$ & $\begin{array}{l}\text { Hearing loss of }>20 \mathrm{~dB} \text { at } 4- \\
\qquad 8 \mathrm{kHz}\end{array}$ & $\begin{array}{c}\text { Hearing loss of }>20 \mathrm{~dB} \\
\text { at } 2-8 \mathrm{kHz}\end{array}$ & $\begin{array}{c}\text { Hearing loss of }>40 \mathrm{~dB} \\
\text { at } 2-8 \mathrm{kHz}\end{array}$ \\
\hline
\end{tabular}


Table 2: Grading scheme used for critical appraisal of evidence

\begin{tabular}{|c|l|l|}
\hline Grade & \multicolumn{1}{|c|}{ Results } & \multicolumn{1}{c|}{ Description } \\
\hline++++ & $\begin{array}{l}\text { Consistent, } \\
\text { generalizable }\end{array}$ & $\begin{array}{l}\text { Strong general conclusions can be drawn that are unlikely to } \\
\text { change based on further research }\end{array}$ \\
\hline+++ & $\begin{array}{l}\text { Consistent, but limited } \\
\text { quantity, quality or } \\
\text { generalizability }\end{array}$ & $\begin{array}{l}\text { Evidence allows general conclusions, but with reduced } \\
\text { confidence; further research is likely to have an important } \\
\text { impact on confidence in conclusions }\end{array}$ \\
\hline++ & $\begin{array}{l}\text { Inconsistent or } \\
\text { insufficient } \\
\text { quantity/quality, } \\
\text { encouraging }\end{array}$ & $\begin{array}{l}\text { No general conclusions can be drawn or conclusions are likely } \\
\text { to change based on further research, but current evidence is } \\
\text { encouraging }\end{array}$ \\
\hline+ & $\begin{array}{l}\text { Inconsistent or } \\
\text { insufficient } \\
\text { quantity/quality, } \\
\text { discouraging }\end{array}$ & $\begin{array}{l}\text { No conclusions can be drawn or conclusions are likely to } \\
\text { change based on future studies, and current evidence is } \\
\text { discouraging }\end{array}$ \\
\hline
\end{tabular}


Table 3: Grading scheme used for clinical practice guidelines

\begin{tabular}{|c|l|l|}
\hline Level & Strength & Evidence basis \\
\hline A & Strong & $\begin{array}{l}\text { Based on strong scientific evidence; benefits clearly outweigh } \\
\text { risks }\end{array}$ \\
\hline B & Moderate & $\begin{array}{l}\text { Based on reduced confidence scientific evidence and expert } \\
\text { opinion; benefits likely to outweigh risks }\end{array}$ \\
\hline C & Optional & $\begin{array}{l}\text { Based mainly on expert opinion, for use with evidence } \\
\text { development in a research context }\end{array}$ \\
\hline
\end{tabular}


Table 4: Summary of genotype-based risk stratification

\begin{tabular}{|l|c|c|c|}
\hline Tested Variant & Genotype & Frequency* & Interpretation \\
\hline TPMT*3C (rs1142345) & G/G & Rare (<1\%) & $\begin{array}{c}\text { Increased risk of Cisplatin- } \\
\text { induced Ototoxicity }\end{array}$ \\
\cline { 2 - 4 } & A/G & Infrequent (0-14\%) & $\begin{array}{c}\text { Increased risk of Cisplatin- } \\
\text { induced Ototoxicity }\end{array}$ \\
\cline { 2 - 5 } & A/A & Common (88-100\%) & $\begin{array}{c}\text { Standard risk for Cisplatin- } \\
\text { induced Ototoxicity }\end{array}$ \\
\hline TPMT*3B (rs1800460) & A/A & Rare (<1\%) & $\begin{array}{c}\text { Increased risk of Cisplatin- } \\
\text { induced Ototoxicity }\end{array}$ \\
\cline { 2 - 5 } & A/G & Infrequent (0-10\%) & $\begin{array}{c}\text { Increased risk of Cisplatin- } \\
\text { induced Ototoxicity }\end{array}$ \\
\cline { 2 - 5 } & G/G & Common (89-100\%) & $\begin{array}{c}\text { Standard risk for Cisplatin- } \\
\text { induced Ototoxicity }\end{array}$ \\
\hline $\begin{array}{c}\text { TPMT*3A haplotype } \\
\text { (rs1142345+ } \\
\text { rs1800460) }\end{array}$ & G/G + A/A & Rare (<1\%) & $\begin{array}{c}\text { Increased risk of Cisplatin- } \\
\text { induced Ototoxicity }\end{array}$ \\
\cline { 2 - 5 } & A/G + A/G & Infrequent (0-10\%) & $\begin{array}{c}\text { Increased risk of Cisplatin- } \\
\text { induced Ototoxicity }\end{array}$ \\
\cline { 2 - 5 } & A/A + G/G & Common (89-100\%) & $\begin{array}{c}\text { Standard risk for Cisplatin- } \\
\text { induced Ototoxicity }\end{array}$ \\
\hline
\end{tabular}

* Range of allele and haplotype frequencies for worldwide ancestries ${ }^{76,77}$ 